\title{
Survival of Mexican Children with Acute Myeloid Leukaemia Who Received Early Intensification Chemotherapy and an Autologous Transplant
}

\author{
Elva Jiménez-Hernández, ${ }^{1}$ María Teresa Dueñas-González, ${ }^{1}$ \\ José Arellano-Galindo, ${ }^{2}$ María Elena Medrano-Ortíz-De-Zárate, ${ }^{3}$ \\ Vilma Carolina Bekker-Méndez, ${ }^{4}$ Adolfina Berges-García, ${ }^{1}$ Karina Solís-Labastida, ${ }^{5}$ \\ Berenice Sánchez-Jara, ${ }^{1}$ Héctor Manuel Tiznado-García, ${ }^{1}$ Ethel Zulie Jaimes-Reyes, ${ }^{1}$ \\ Xochiketzalli García-Jiménez, ${ }^{6}$ Laura Espinoza-Hernández, ${ }^{1}$ Nora Nancy Núñez-Villegas, ${ }^{1}$ \\ Sergio Franco-Ornelas, ${ }^{1}$ Ruy Xavier Pérez-Casillas, ${ }^{1}$ Octavio Martínez Villegas, ${ }^{1}$ \\ Teresa Marin Palomares, ${ }^{1}$ and Juan Manuel Mejía-Aranguré ${ }^{7}$ \\ ${ }^{1}$ Departamento de Hematología Pediátrica, Unidad Médica de Alta Especialidad (UMAE), \\ Centro Médico Nacional "La Raza", Instituto Mexicano del Seguro Social (IMSS), Avenida Jacarandas Esquina Vallejo, \\ S/N, Colonia La Raza, 02990 México, DF, Mexico \\ ${ }^{2}$ Laboratorio de Investigación, Hospital Infantil de México "Federico Gómez", Secretaría de Salud, Calle Doctor Marquez 162, \\ Colonia Doctores, Delegación Cuauhtémoc, 06720 México, DF, Mexico \\ ${ }^{3}$ Hospital de Oncología, Centro Médico Nacional "Siglo XXI", IMSS, Avenida Cuauhtemoc 330, 06720 México, DF, Mexico \\ ${ }^{4}$ Unidad de Investigación en Inmunología, Unidad Médica de Alta Especialidad (UMAE), Centro Médico Nacional "La Raza", \\ Instituto Mexicano del Seguro Social (IMSS), Avenida Jacarandas Esquina Vallejo, S/N, Colonia La Raza, \\ 02990 México, DF, Mexico \\ ${ }^{5}$ Hematología Pediátrica, Centro Médico Nacional “Siglo XXI”, IMSS, Avenida Cuauhtemoc 330, \\ 06720 México, DF, Mexico \\ ${ }^{6}$ Facultad de Medicina, Universidad Nacional Autónoma de México, Avenida Universidad 3000, \\ 04510 México, DF, Mexico \\ ${ }^{7}$ Unidad de Investigación en Epidemiología Clínica, UMAE Hospital de Pediatría, Centro Médico Nacional "Siglo XXI", IMSS, \\ Avenida Cuauhtemoc 330, 4to Piso Edificio de la Academia Nacional de Medicina, 06720 México, DF, Mexico \\ Correspondence should be addressed to Juan Manuel Mejía-Aranguré; juan.mejiaa@imss.gob.mx
}

Received 30 June 2014; Revised 23 October 2014; Accepted 2 November 2014

Academic Editor: Richard J. Q. McNally

Copyright (c) 2015 Elva Jiménez-Hernández et al. This is an open access article distributed under the Creative Commons Attribution License, which permits unrestricted use, distribution, and reproduction in any medium, provided the original work is properly cited.

Background. In Mexico and other developing countries, few reports of the survival of children with acute leukaemia exist. Objective. We aimed at comparing the disease-free survival of children with acute myeloid leukaemia who, in addition to being treated with the Latin American protocol of chemotherapy and an autologous transplant, either underwent early intensified chemotherapy or did not undergo such treatment. Procedure. This was a cohort study with a historical control group, forty patients, less than 16 years old. Group A (20 patients), diagnosed in the period 2005-2007, was treated with the Latin American protocol of chemotherapy with an autologous transplant plus early intensified chemotherapy: high doses of cytarabine and mitoxantrone. Group B (20 patients), diagnosed in the period 1999-2004, was treated as Group A, but without the early intensified chemotherapy. Results. Relapse-free survival for Group A was $90 \%$ whereas that for Group B it was $60 \%(P=0.041)$. Overall survival for Group A $(18,90 \%)$ was higher than that for Group B (60\%). Complete remission continued for two years of follow-up. Conclusions. Relapse-free survival for paediatric patients treated with the Latin American protocol of chemotherapy with an autologous transplant plus early intensified chemotherapy was higher than that for those who did not receive early intensified chemotherapy. 


\section{Background}

The importance of acute myeloid leukaemia (AML) is evident because, although comprising only $15 \%-20 \%$ of childhood leukaemias, the mortality rates of AML account for up to $30 \%$ of leukaemia-related deaths [1-3]. In the past three decades, the prognosis of paediatric AML has improved significantly because of progress in the treatment of this disease, principally through the introduction of regimens of multidrug use and of intensification therapy and through improvement in postremission therapy and in support care. Despite these improvements, the accumulated risk of relapse is still approximately $30 \%-40 \%$ [4].

When administered alone, chemotherapy in paediatric AML has improved the probability of event-free survival (EFS); however, even in the best series published in the last decade, EFS reached only $31 \%-54 \%$ with the probability of overall survival (OS) between $36 \%$ and $66 \%$ [5-17]. When chemotherapy is combined with autologous haematopoietic transplantation, similar results are obtained; however, the importance of this combinatory treatment lies in its demonstrated ability to lower the risk of relapse [18-20]. Although allogeneic haematopoietic transplantation offers a higher probability of cure (up to $67 \%$ ), its use in primary remission in groups with good risk is not recommended, because of its morbidity-mortality and because its use has not shown better results than chemotherapy alone $[8,12,16,19,21,22]$. When the patients are stratified by independent prognostic indicators, groups with chromosomal aberrations indicative of good risk, such as $\mathrm{t}(8: 21)$, inv (16), and $\mathrm{t}(15: 17)$, can reach an OS of $91 \%, 92 \%$, and $87 \%$, respectively $[23,24]$.

Although the results with autologous transplants are similar to those with chemotherapy alone and their use is controversial, some groups that have obtained results either superior to those of chemotherapy alone or similar to those of allogeneic transplant retain their interest in the use of autologous transplants [25-30], because not only is the need for an HLA-identical donor obviated, but also the potentially fatal graft versus host disease is avoided.

However, there are disadvantages, such as a lack of effect of the graft against the leukaemia and the risk of reinfusion of leukaemia cells, bringing with them a greater risk of relapse. To reduce the latter possibility, various techniques of purge ex vivo or purge in vivo have been developed [31-34]. With the purge in vivo, together with the harvest of peripheral blood stem cells (PBSC), the risk of harvesting neoplastic cells is reduced; as a consequence, the risk of relapse from the disease is also reduced $[34,35]$. When a patient previously received various cycles of intensification chemotherapy, even better results have been obtained [25, 27, 36, 37].

In the present study, the patients with AML, starting in 1999, received chemotherapy (called the Latin American protocol) that was based on the protocol of the German group (AML-Berlin-Frankfurt-Münster (BFM) 87 [38]) plus autologous transplantation in first remission, resulting in a fiveyear survival rate of $60 \%$; starting in 2005, patients received, in addition to this standard treatment, a cycle of early intensification (EI) chemotherapy with high doses of cytarabine (Ara-C) and mitoxantrone (HAM) (AML-BFM 93) [39]. The objective of the present study was to compare the diseasefree survival of children with AML who, in addition to being treated with the Latin American protocol of chemotherapy and an autologous transplant, either underwent EI chemotherapy or did not undergo such treatment.

\section{Methods}

2.1. Study Design. Cohort study for assessing survival: the Hematological Service of the General Hospital of the National Medical Center "La Raza" in Mexico City is the facility that treats the greatest number of patients with leukaemia in the whole Mexico. This project was approved by the Ethics and Research Committee of the General Hospital of the National Medical Center "La Raza," Mexico City (number R20083502-63). Written consent from the parents of the patients was obtained when the children were first admitted to the hospital.

2.2. Patient Groups. All patients were less than 16-year-old. Group A $(n=20)$ comprised those patients who had been diagnosed with AML for the first time from January 2005 to December 2007. Group B $(n=20)$ consisted of those patients diagnosed with AML for the first time from January 1999 to December 2004. The composition of the cohorts is described in Figure 1. The patients were included when they the complete remission in all subtypes since M0 to M7 was reached and only to M3 when the patients had the second remission reached or when the PLM/RAR $\alpha$ was negative.

The French-American-British (FAB) classification was used for the initial diagnosis and the microscopy determinations were corroborated by at least three haematologist observers; the subtypes, M0 and M7, were confirmed by immunologic methods; bone marrow aspirates taken on Day 15 were examined by two or more haematologists.

2.3. Risk Classification. The classification of risk was conducted according to the criteria of group AML-BFM 93 [40]. Patients at low risk were those with morphological subtypes M1, M2 (with Auer bodies) or t(8:21), as well as M4 with eosinophilia and 16 inversion in the karyotype, and if they had $<5 \%$ blast cells in the bone marrow on Day 15 of induction of remission (IR). Patients with high risk were those, that morphologically were clasified as M1, M2, or M4, additionally in patients M4 and without characteristic mentioned above. With either $>5 \%$ blast cells in the bone marrow on Day 15 of IR; with monosomy 7, 5 in the karyotype; or with complex karyotypes.

2.4. Response Criteria. The criteria used were those of the International Working Group for the Diagnosis and Treatment of AML [41]. Complete haematological remission: no clinical evidence of leukaemia; bone marrow with restoration of normal haematopoiesis, with $<5 \%$ blast cells; and, in the peripheral blood, $\geq 1500$ neutrophils $/ \mu \mathrm{L}$ and $\geq 100000$ platelets/ $\mu \mathrm{L}$ without transfusion. Early death: if death occurred when treatment was not initiated, or if death occurred less than seven days after having finished the first cycle of 


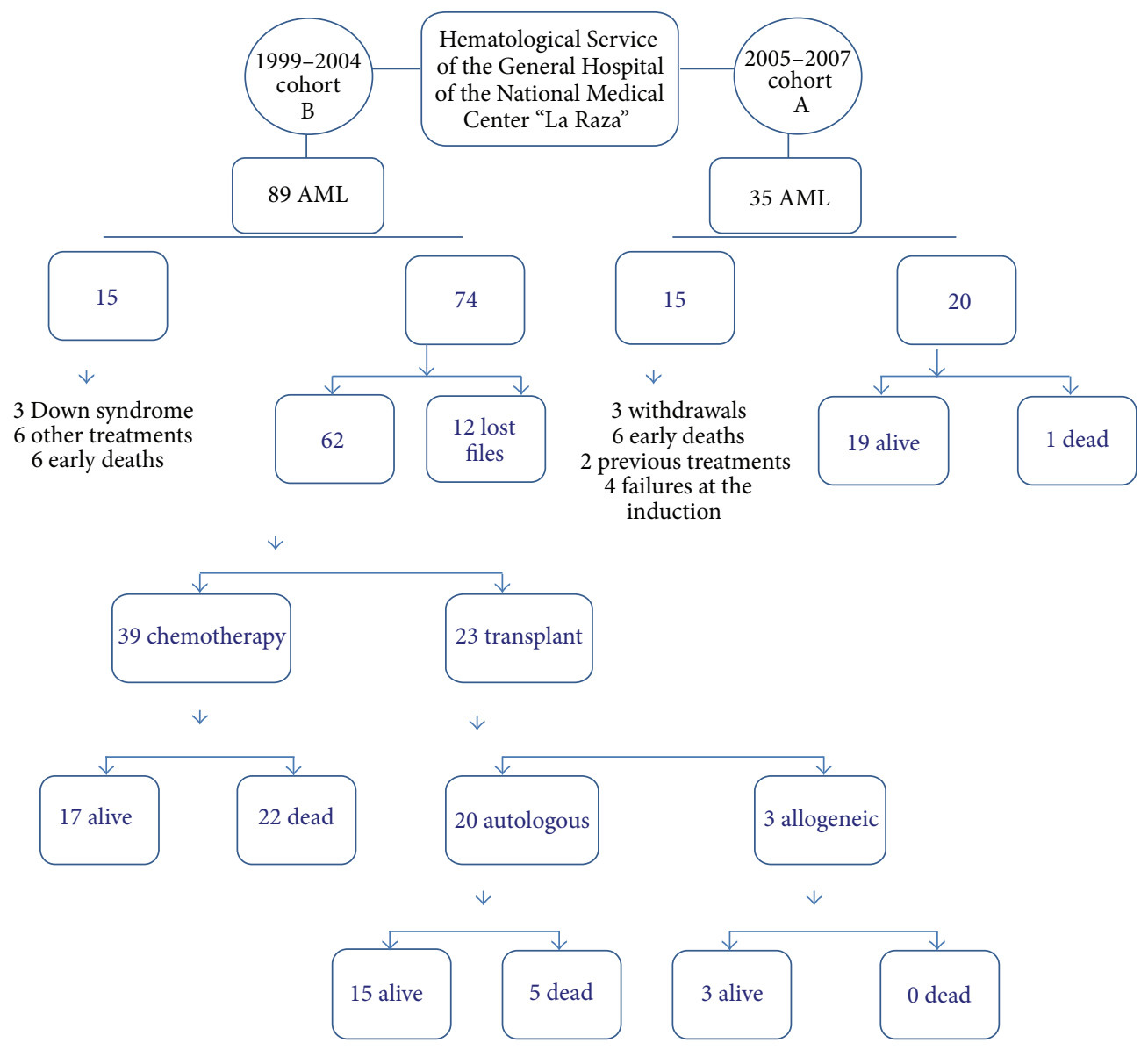

Figure 1: Patient selection. Group A (20 patients), diagnosed in the period 2005-2007, was treated with the Latin American protocol of chemotherapy with an autologous transplant plus early intensified chemotherapy: high doses of cytarabine and mitoxantrone (HAM). Group B (20 patients), diagnosed in the period 1999-2004, was treated as Group A but without the early intensified chemotherapy. AML: acute myeloid leukaemia.

IR. Death during treatment: death during treatment with hypoplastic bone marrow. Therapeutic failure: persistence of leukaemia after having received two cycles of chemotherapy for IR. Relapse-free survival (DFS): the time that elapsed from complete remission until the haematological, genetic, or molecular detection of relapse of the disease. Relapse: after remission was declared, reemergence of the disease as indicated by blast cells in the peripheral blood, $\geq 5 \%$ of blast cells in the bone marrow, or extramedullary infiltration. Overall survival (OS): the time elapsed from the date of diagnosis until the most recent follow-up. Toxicity of the chemotherapy was evaluated in accordance with the criteria of the US National Cancer Institute (NCI) [42].

2.5. Treatment. The schematic of chemotherapy (Supplemental Figure I, see Supplementary Material available online at http://dx.doi.org/10.1155/2015/940278) which for Group B was based on the Latin American protocol (AML-BFM 87) [38] and which for Group A was based on AML-BFM 93 [39], with the following modifications: 6-thioguanine was not used in the consolidation, because this drug is not available in Mexico; prophylactic radiation of the central nervous system
(CNS) was not administered, because it was not considered necessary as, historically, the number of relapses in the Hematological Service is very low for the type of patients treated. Patients in both groups underwent an autologous transplant in first complete remission (CR1). The toxicity related to this regimen was investigated by using the NCI criteria [42].

2.6. Statistical Analysis. For the quantitative variables without normal distribution, a Mann-Whitney $U$ test was used for comparison of two independent groups; for qualitative variables, $\chi^{2}$ or Fisher's exact test was used. $P<0.05$ was considered statistically significant. The Kaplan-Meier method was used to construct survival plots; a log-rank test was used for comparison between groups.

We analysed the following potential variables that influence relapse: age, sex, leukocyte count at diagnosis, response on Day 15 of the IR, time from diagnosis to complete remission (CR), low or high risk, the cycles of chemotherapy required to achieve remission, time of remission to transplant, quantity of $\mathrm{MNC} \times 10^{8} / \mathrm{kg}$, and quantity of CD34+ $\times$ $10^{6} / \mathrm{kg}$. For these variables, the crude relative risk (CRR), the CRR by strata, and the CRR, adjusted by Mantel-Haenszel 
TABLE 1: General and clinical characteristics of the paediatric patients with acute myeloid leukaemia.

\begin{tabular}{|c|c|c|c|}
\hline \multirow[b]{2}{*}{ Characteristic } & \multicolumn{2}{|c|}{ Patients } & \multirow[b]{2}{*}{$P$} \\
\hline & $\begin{array}{c}\text { Group A with } \mathrm{EI}^{\mathrm{a}} \\
\quad(n=20)\end{array}$ & $\begin{array}{l}\text { Group B without EI } \\
\qquad(n=20)\end{array}$ & \\
\hline Age (years) & & & 0.718 \\
\hline Median (min-max) & $9(2-15)$ & $9.5(2-15)$ & \\
\hline Sex & & & 0.525 \\
\hline Male & $11(55 \%)$ & $11(55 \%)$ & \\
\hline Female & $9(45 \%)$ & $9(45 \%)$ & \\
\hline Leukocyte count $\left(10^{3} / \mu \mathrm{L}\right)$ & & & 0.698 \\
\hline Median & 28250 & 26900 & \\
\hline Minimum-maximum & $9700-125000$ & $5800-154700$ & \\
\hline Morphological subtype $\left(\mathrm{FAB}^{\mathrm{b}}\right)$ & & & 0.941 \\
\hline M0, M1, M2 & $6(30 \%)$ & $4(20 \%)$ & \\
\hline M3 & $1(5 \%)$ & $1(5 \%)$ & \\
\hline M4, M5 & $11(55 \%)$ & $12(60 \%)$ & \\
\hline M6 & $1(5 \%)$ & $1(5 \%)$ & \\
\hline M7 & $1(5 \%)$ & $2(10 \%)$ & \\
\hline Karyotype & & & 0.900 \\
\hline Normal & $8(40 \%)$ & $6(30 \%)$ & \\
\hline $\mathrm{t}(8: 21) \mathrm{aml} / \mathrm{atg} 8$ & $2(10 \%)$ & $3(15 \%)$ & \\
\hline $\mathrm{t}(15: 4) \mathrm{q}+$ & $0(0 \%)$ & $1(5 \%)$ & \\
\hline $\mathrm{t}(9: 22) \mathrm{abr} / \mathrm{bcl}$ & $1(5 \%)$ & $1(5 \%)$ & \\
\hline $\mathrm{t}(9: 11) \mathrm{p} 22, \mathrm{q} 23$ & $1(5 \%)$ & $1(5 \%)$ & \\
\hline No data & $8(40 \%)$ & $8(40 \%)$ & \\
\hline Risk (by karyotype) & & & 0.870 \\
\hline Normal & $4(17 \%)$ & $3(13 \%)$ & \\
\hline Intermediate & $8(33 \%)$ & $6(25 \%)$ & \\
\hline High & $2(8 \%)$ & $1(4 \%)$ & \\
\hline Risk $\left(\mathrm{BFM}^{\mathrm{c}}\right)$ & & & 0.669 \\
\hline Low & $3(15 \%)$ & $3(15 \%)$ & \\
\hline High & $17(85 \%)$ & $17(85 \%)$ & \\
\hline
\end{tabular}

${ }^{\mathrm{a} E I}$ : early intensification.

${ }^{b}$ FAB: French-American-British classification.

${ }^{c}$ BFM: Berlin-Frankfurt-Münster study [39].

statistics, with confidence intervals of 95\%, were calculated in two-by-two tables. The statistical package SPSS version 21 was used.

\section{Results}

3.1. General Characteristics of the Patients. In this study, no significant differences were found between the groups $(20$ patients per group) for any of the general or clinical characteristics analysed (Table 1). For the two groups, the median age was nine years; the distribution by sex was similar; the median leukocyte count at diagnosis was $28250 / \mu \mathrm{L}$ for Group A and $26900 / \mu \mathrm{L}$ for Group B $(P=0.698)$. In both groups, the most common morphological subtypes were M4 and M5, which together comprised 55\% of the cases in Group A and $60 \%$ in Group B. Of the 40 patients, 35\% had a normal karyotype; five had a low-risk karyotype $(\mathrm{t}(8: 21))$, and three had a high-risk karyotype. According to the risk classification of the BFM group, 34 patients had high-risk parameters.

\subsection{Primary Results: Response to Treatment}

3.2.1. Relapse-Free Survival after an Autologous Transplant. Relapse-free survival (Figure 2) was $90 \%$ for Group A and $60 \%$ for Group B ( $P=0.041)$; these patients were in complete continuous remission (CCR), with a median follow-up time of 405 days for Group A and 527 days for Group B. Of the 10 patients who suffered a relapse (Table 2), the relapse occurred in the bone marrow of eight, in the CNS of one, and in both sites in another; none of these 10 attained a second remission and all died from leukaemic activity.

3.2.2. Overall Survival. The overall survival (OS) (Figure 3) was 18 (90\%) for Group A with a median duration of followup of 610 days (minimum, 226; maximum, 730). For Group B, 


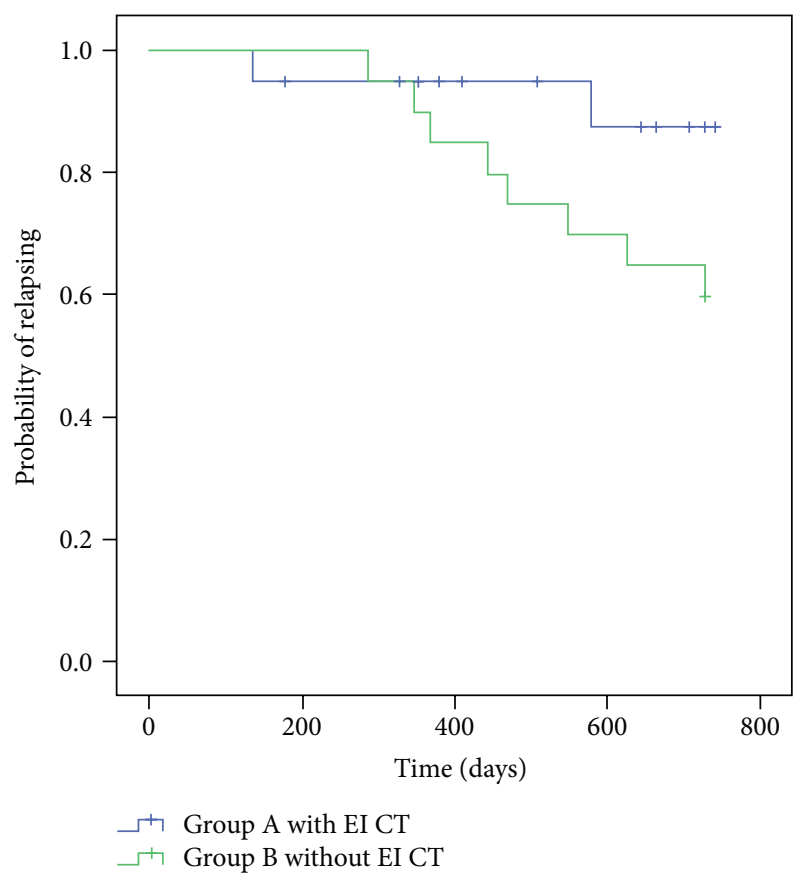

FIGURE 2: Relapse-free survival after autologous transplant for patients treated with early intensification chemotherapy or not. EI: early intensification; CT: chemotherapy. $P=0.09$.

TABLE 2: Outcomes for paediatric patients with acute myeloid leukaemia, treated with early intensification chemotherapy or not.

\begin{tabular}{|c|c|c|c|}
\hline \multirow[b]{2}{*}{ Parameter } & \multicolumn{2}{|c|}{ Patients } & \multirow[b]{2}{*}{$P$} \\
\hline & $\begin{array}{l}\text { Group A with } \mathrm{EI}^{\mathrm{a}} \\
\qquad(n=20)\end{array}$ & $\begin{array}{l}\text { Group B } \\
\text { without EI } \\
(n=20)\end{array}$ & \\
\hline $\mathrm{CCR}^{\mathrm{b}}$ & $18(90 \%)$ & $12(60 \%)$ & 0.028 \\
\hline \multicolumn{4}{|l|}{ Relapse } \\
\hline Pretransplant & $1(5 \%)$ & $0(0 \%)$ & \\
\hline Posttransplant & $1(5 \%)$ & $8(40 \%)$ & 0.031 \\
\hline \multicolumn{4}{|l|}{ Site of relapse } \\
\hline $\mathrm{BM}^{\mathrm{c}}$ & $2(10 \%)$ & $6(30 \%)$ & 0.030 \\
\hline $\mathrm{CNS}^{\mathrm{d}}$ & $0(0 \%)$ & $1(5 \%)$ & \\
\hline $\mathrm{BM}+\mathrm{CNS}$ & $0(0 \%)$ & $1(5 \%)$ & \\
\hline \multicolumn{4}{|l|}{ Current state } \\
\hline Alive with CCR & $18(90 \%)$ & $12(60 \%)$ & 0.028 \\
\hline Dead & $2(10 \%)$ & $8(40 \%)$ & 0.031 \\
\hline \multicolumn{4}{|l|}{ Cause of death } \\
\hline Leukaemic activity & $2(100 \%)$ & $8(100 \%)$ & 0.031 \\
\hline Related to APBT & $0(0 \%)$ & $0(0 \%)$ & \\
\hline $\begin{array}{l}\text { EI: early intensification. } \\
{ }^{\mathrm{b}} \text { CCR: continued complet } \\
{ }^{\mathrm{c}} \mathrm{BM} \text { : bone marrow. } \\
{ }^{\mathrm{d}} \text { CNS: central nervous sys } \\
{ }^{\mathrm{e}} \text { APBT: autologous periph }\end{array}$ & e remission. & & \\
\hline
\end{tabular}

the OS was $12(60 \%)$, with a median follow-up of 675 days (minimum, 376; maximum, 730) ( $P=\mathrm{NS}$ ).

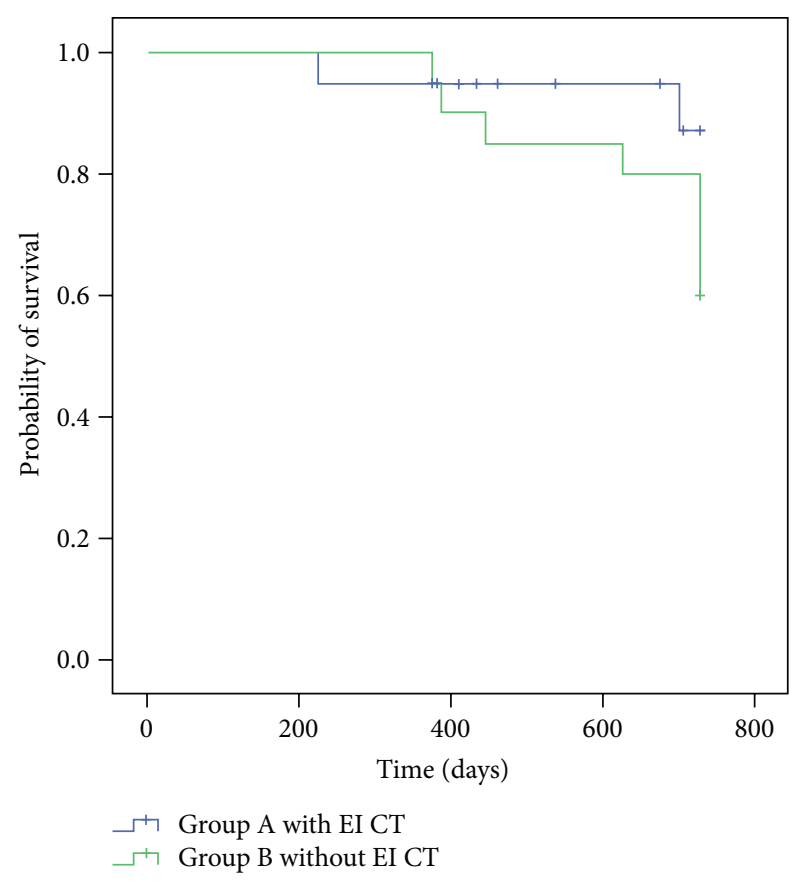

FIGURE 3: Overall survival at two years of follow-up for patients treated with early intensification chemotherapy or not. EI: early intensification; CT: chemotherapy. $P=0.13$.

3.2.3. Variables Associated with Relapse. Analysis of the variables that could influence relapse showed that none of these variables affected the risk, whether calculated as CRR or as that adjusted by Mantel-Haenszel statistics (Table 3).

\subsection{Secondary Results: Toxicity of EI Chemotherapy in Group} $A$. No patient died from treatment toxicity; nor were any excluded from the study for this reason. All 20 (100\%) displayed fever and neutropenia and required empirical treatment with wide-spectrum antibiotics; 12 of these patients were given amphotericin B for having persistent fever for more than five days, despite the use of the antibiotics. Two other patients suffered pneumonia; two had neutropenic enterocolitis that responded to antibiotics; and only one developed systematic candidiasis, which was resolved with amphotericin B and that did not influence the transplant. All patients presented haemorrhage of the skin and mucosa; seven had blood in the digestive tract (haematemesis or bleeding from the rectum) that was resolved with the transfusion of platelets.

3.4. Harvest of Haematopoietic Stem Cells. The characteristics of the harvested of autologous hematopoietic stem cells from pediatric patients are shown in Supplemental Table I. Neither the MNC nor the CD34+ cell count differed between groups $(P=0.70)$. There were no differences between groups for any of the other parameters studied.

3.5. Transplant of Haematopoietic Stem Cells. Of the 20 patients in Group A, who were programmed for an autologous transplant, a patient with AML-M2 (karyotype 
TABLE 3: Parameters analyzed for relapse adjusted by different prognostic factors.

\begin{tabular}{|c|c|c|c|c|c|c|c|}
\hline \multirow{3}{*}{ Variable } & \multicolumn{4}{|c|}{ Patients } & & & \\
\hline & \multicolumn{2}{|c|}{ Group A with $\mathrm{EI}^{\mathrm{a}}(n=20)$} & \multicolumn{2}{|c|}{ Group B without EI $(n=20)$} & \multicolumn{3}{|c|}{ Crude relative risk } \\
\hline & $\begin{array}{c}\text { No relapse } \\
n(\%)\end{array}$ & $\begin{array}{l}\text { Relapse } \\
n(\%)\end{array}$ & $\begin{array}{c}\text { No relapse } \\
n(\%)\end{array}$ & $\begin{array}{c}\text { Relapse } \\
n(\%)\end{array}$ & $\mathrm{CRR} \times \mathrm{S}^{\mathrm{b}}(\mathrm{CI} 95 \%)$ & $\mathrm{RR}$ & $(\mathrm{CI} 95 \%)$ \\
\hline$<10$ & $10(90.9)$ & $1(9.1)$ & $7(58.3)$ & $5(41.7)$ & $0.22(0.03-1.59)$ & & \\
\hline$>10$ & $8(88.9)$ & $1(11.1)$ & $5(62.5)$ & $3(37.5)$ & $0.30(0.04-2.31)$ & 0.25 & $(0.06-1.11)$ \\
\hline \multicolumn{8}{|l|}{ Sex } \\
\hline Female & $8(88.9)$ & $1(11.1)$ & $9(100)$ & $0(0.0)$ & $2.00(0.21-18.98)$ & & \\
\hline Male & $10(90.9)$ & $1(9.1)$ & $3(27.3)$ & $8(72.7)$ & $0.22(0.06-0.84)$ & 0.40 & $(0.14-1.11)$ \\
\hline \multicolumn{8}{|l|}{ Leukocytes } \\
\hline$<50000 / \mu \mathrm{L}$ & $15(100)$ & $0(0.0)$ & $10(62.5)$ & $6(37.5)$ & $0.15(0.20-1.10)$ & & \\
\hline$>50000 / \mu \mathrm{L}$ & $3(60.0)$ & $2(40.0)$ & $2(50.0)$ & $2(50.0)$ & $1.14(0.40-3.18)$ & 0.47 & $(0.18-1.18)$ \\
\hline \multicolumn{8}{|l|}{$\mathrm{BM}^{\mathrm{d}}$ Day 15} \\
\hline$<5 \%$ blasts & $11(91.7)$ & $1(8.3)$ & $10(71.4)$ & $4(28.6)$ & $0.29(0.37-2.26)$ & & \\
\hline$>5 \%$ blasts & $7(87.5)$ & $1(12.5)$ & $2(33.3)$ & $4(66.7)$ & $0.18(0.02-1.27)$ & 0.23 & $(0.05-0.94)$ \\
\hline \multicolumn{8}{|l|}{ Risk } \\
\hline Low & $3(100)$ & $0(0.0)$ & $3(100)$ & $0(0.0)$ & $1.00(0.08-11.9)$ & & \\
\hline High & $15(88.2)$ & $2(11.8)$ & $9(52.9)$ & $8(47.1)$ & $0.33(0.10-1.04)$ & 0.40 & $(0.14-1.10)$ \\
\hline \multicolumn{8}{|l|}{ Time of $\mathrm{CR}^{\mathrm{e}}$} \\
\hline$<8$ weeks & $14(93.3)$ & $1(6.7)$ & $9(64.3)$ & $5(35.7)$ & $0.18(0.02-1.40)$ & & \\
\hline$>8$ weeks & $4(80.0)$ & $1(20.0)$ & $3(50.0)$ & $3(50.0)$ & $0.40(0.59-2.74)$ & 0.26 & $(0.06-1.04)$ \\
\hline \multicolumn{8}{|l|}{$\mathrm{CT}^{\mathrm{f}}$ for $\mathrm{CR}$} \\
\hline One cycle & $11(91.7)$ & $1(8.3)$ & $10(66.7)$ & $5(33.3)$ & $0.25(0.03-1.86)$ & & \\
\hline Two cycles & $7(87.5)$ & $1(12.5)$ & $2(40.0)$ & $3(60.0)$ & $0.20(0.02-1.49)$ & 0.23 & $(0.05-0.95)$ \\
\hline \multicolumn{8}{|c|}{ CR upon $\mathrm{APBT}^{\mathrm{g}, \mathrm{h}}$} \\
\hline$>10$ months & $9(90.0)$ & $1(10.0)$ & $4(57.1)$ & $3(42.9)$ & $0.37(0.87-1.61)$ & & \\
\hline$<10$ months & $9(100)$ & $0(0.0)$ & $8(61.5)$ & $5(38.5)$ & $0.15(0.02-1.14)$ & 0.26 & $(0.82-0.83)$ \\
\hline \multicolumn{8}{|c|}{$\operatorname{MNC}^{\mathrm{h}, \mathrm{i}}\left(10^{8} / \mathrm{kg}\right)$} \\
\hline$<5$ & $14(93.3)$ & $1(6.7)$ & $8(66.7)$ & $4(33.3)$ & $0.32(0.07-1.44)$ & & \\
\hline$>5$ & $4(100)$ & $0(0.0)$ & $4(50.0)$ & $4(50.0)$ & $0.33(0.10-1.06)$ & 0.33 & $(0.10-1.06)$ \\
\hline \multicolumn{8}{|c|}{ CD $34+$ cells $^{\mathrm{h}}\left(10^{6} / \mathrm{kg}\right)$} \\
\hline$>3$ & $3(100)$ & $0(0.0)$ & $3(60.0)$ & $2(40.0)$ & $0.46(0.06-3.23)$ & & \\
\hline$<3$ & $15(93.8)$ & $1(6.3)$ & $9(60.0)$ & $6(40.0)$ & $0.26(0.06-1.12)$ & 0.32 & $(0.10-1.00)$ \\
\hline
\end{tabular}

${ }^{a}$ EI: early intensification.

${ }^{\mathrm{b}} \mathrm{CRR} \times \mathrm{S}$ : crude relative risk by strata.

${ }^{c} \mathrm{CR}(\mathrm{MH})$ : relative risk, adjusted (Mantel-Haenszel).

${ }^{\mathrm{d}} \mathrm{BM}$ : bone marrow.

${ }^{\mathrm{e}} \mathrm{CR}$ : complete remission.

${ }^{\mathrm{f}} \mathrm{CT}$ : chemotherapy.

${ }^{g}$ APBT: autologous peripheral blood transplant.

${ }^{\mathrm{h}}$ Only 19 patients in Group A received transplant (see text for details).

${ }^{\mathrm{i}} \mathrm{MNC}$ : mononuclear cell.

$t(9 ; 11) p 22 ; q 23)$ did not have the procedure because of a bone marrow relapse; the patient died as a result of infection and leukaemic activity eight months after diagnosis. It is for this reason that only 19 patients in Group A received transplants. (No patient died from the toxicity of the EI. One other patient died from infection at another stage of treatment because of leukaemic activity.) For these 19 patients, the median time from complete remission to transplant was 9.9 months (minimum, 6.1; maximum, 12.8), whereas for Group B $(n=20)$, the median was 8.6 months (minimum, 5.6; maximum 15.7) $(P=0.235)$; thus, EI chemotherapy did not cause a major delay in transplantation. 
All these patients received an adequate transplant; the median number of days needed to reach a polymorphonuclear cell count $\geq 0.5 \times 10^{9} / \mathrm{L}$ was 18 days (minimum, 12; maximum, 35) for Group A and 18 days (minimum, 14; maximum, 38) for Group B ( $P=0.749)$; to reach a platelet cell count $\geq 50 \times 10^{9} / \mathrm{L}$, without transfusion, the median number of days needed was 23 (minimum, 18; maximum, 54). The patients received G-CSF after the infusion of the harvested cells; on Day +18 , five patients from Group A and four from Group B did not have a neutrophil count $\geq 0.5 \times 10^{9} / \mathrm{L}$.

3.6. Complications and Mortality Related to the Transplant. Of the 39 patients who received transplants, 12 (31\%) did not present any complications; $12(31 \%)$ developed a fever that lasted more than seven days and with neither a localized site of infection nor an isolated microorganism, thus warranting the use of wide-spectrum antibiotics (ceftazidime/amikacin or vancomycin); and eight (21\%) required amphotericin $\mathrm{B}$. Mortality as a result of transplantation was $0 \%$.

\section{Discussion}

The study AML-BFM 93 [39] found that the combination of idarubicin in the induction and the intensification therapy with HAM reduces the risk of relapse in patients at high risk. The other factor that probably was potentiated by the EI was the prolonged average time (270 days) from remission to transplant, as was demonstrated by Locatelli et al. [43]. In that multivariate analysis, it was shown that, of the children who had transplants at $\geq 170$ days after the first CR, $60 \% \pm 3 \%$ had a leukaemia-free survival during five years of follow-up. This beneficial effect may be the result of two principal factors: (1) additional useful courses of consolidation to reduce the tumour burden and (2) the low risk of mortality related to the transplants in these patients, which is because of the sufficient time for organic recovery before the transplantation.

Other studies have demonstrated the effectiveness of HAM in treating AML, both in children and in adults. The GALGB study was the first to show the effect of cytarabine at a standard dose $\left(100 \mathrm{mg} / \mathrm{m}^{2}\right)$, intermediate dose $\left(400 \mathrm{mg} / \mathrm{m}^{2}\right)$, or high dose $\left(3 \mathrm{~g} / \mathrm{m}^{2}\right)$ as treatment postremission [44]. Thereafter, Arlin et al. [45] reported a higher average of CR after only one course of induction with Ara-C and mitoxantrone $\left(3 \times 12 \mathrm{mg} / \mathrm{m}^{2}\right)$, when these drugs were administered after a standard regimen of daunorubicin $\left(3 \times 45 \mathrm{mg} / \mathrm{m}^{2}\right)$ in adult patients with newly diagnosed AML. Büchner et al. [46] demonstrated that HAM as a course for second induction in adults benefits patients at high risk; here, we had similar results for high-risk paediatric patients. In the AML-BFM 93 study, Creutzig et al. [39] evaluated HAM as a first or second cycle of postinduction treatment, with the intention of improving the results in children with AML of high risk. They found no statistically significant difference between the results obtained with the early or late administration of HAM; nevertheless, upon comparison with results of the historic group (AML-BFM 87 [38]), the differences were greater in OS and RFS of up to five years $(60 \% \pm 3 \%, 51 \% \pm 2 \%$, and $62 \% \pm$ $3 \%$, resp.). Similar values were found in the present study.
In the present study, no patient died or was excluded because of toxicity of the treatment; nor was there a significant delay in conducting the autologous transplantation. These results differ from those of AML-BFM 93 [39]. Nonetheless, the incidence of deaths related to the therapy was similar to that in AML-BFM 87 [38]. Therefore, because of the efficacy of HAM and its tolerable average toxicity in children at high risk, in the study AML-BFM 98 [47], HAM was introduced as a second course of therapy for all paediatric patients with AML, including patients with standard risk, with the objective of improving the average survival.

An important finding emerged from the present study, namely, the positive role of EI therapy, followed by a course of consolidation and two courses of late intensification before the harvesting of PBSC and autologous transplant, resulting in a significantly lower estimated probability of relapse $(10 \%)$ compared with that of patients in the control group that received PBSCT without EI (40\%; $P=0.04)$ (relative risk $=$ 0.25, 95\% CI 0.06-1.03).

Intensive chemotherapy coupled with an autologous transplant in primary remission constitutes a good option for treatment. However, the results in the literature vary and are difficult to compare because of the heterogeneity of the studies. They differ in design, number of patients, age of patients, intensity of the courses of chemotherapy before of the transplant, accumulated doses of the most important drugs (anthracyclines, cytarabine, and etoposide), prophylaxis of the CNS, difference in the stratification of risk, the time at which the transplant was performed, the conditioning regimens, the origin of the stem cells, and the use (or not) of a purge [25-37]. In the present study, with the use of EI chemotherapy, a cycle of consolidation, and two late intensifications before the harvest and autologous transplant, the RFS at two years was $90 \%$ compared with $60 \%$ for the control group that had not received such treatment $(P=0.03$; Table 2). Previously, the efficacy of EI as a purge in vivo in children and adults who were newly diagnosed with AML and who received PBSCT was evaluated [36]. They reported that, for the patients who received EI before the harvesting and the transplant compared with patients who did not, the DFS rates were $68.8 \% \pm 10.27 \%$ versus $35.5 \% \pm 12.6 \%$, respectively $(P=$ 0.04). They concluded that, with the use of EI and PBSCT, the risk of relapse was reduced significantly. However, the majority of research groups do not recommend an autologous transplant as postremission therapy in paediatric patients with AML in CR1, because they have not found any benefit compared with that of chemotherapy alone [18, 39, 47].

With the best support care, the mortality related to transplant toxicity has been reduced to $<5 \%$; in the present study, it was $0 \%$, equal to that reported in the literature [ 25 , $26,29]$. With the use of nonpurged and noncryopreserved PBSC in this study, the toxicity and the cost were reduced without interfering with the time of implant, as has been reported by Ruiz-Argüelles et al. [48] and Gómez-Almaguer [49]. Allogeneic transplant continues to be recommended for those paediatric patients with AML at high risk in CR1, who can count on having an HLA-identical family member, because the survival is $61 \%$ at five years of follow-up [50]. 
The following limitations apply to this study. Because the zero point for the cohort was defined when CR was achieved, it may be that those patients who were not included for reasons such as early death, failure of the IR, and nonacceptance of treatment were probably those at higher risk of relapse. Although the two groups had similar general and clinical characteristics, the comparison with the historic group may have been biased because of improvements over time, in support care, and with greater experience in management. In Group A, the follow-up time was short: not all the patients completed the minimum time established for follow-up (two years), which is the time of greatest risk of relapse; after then the probability of cure increases up to $80 \%$. This was observed in the historic group of this study and was recently reported by Majhail et al. [20]. Finally, it is important to emphasize that there are various groups (e.g., in Argentina (GATLA), Chile (PINDA), and Mexico [17]) that do not include EI (HAM) in their chemotherapy plan. From the results of the present work, we recommend the use of EI (HAM) in chemotherapy.

\section{Conflict of Interests}

The authors declare that there is no conflict of interests regarding the publication of this paper.

\section{Acknowledgments}

This study was partially funded by the CONACYT (SALUD2010-1-141026) and by Mexican Institute of Social Security, Grants FIS/IMSS/PROT/PRIO/11/017 and FIS/IMSS/PROT/ G12/1134 (all to Juan Manuel Mejía-Aranguré). Funding to cover the costs of the translation and publishing was provided by the División de Desarrollo de la Investigación del IMSS.

\section{References}

[1] U. Bacher, S. Schnittger, and T. Haferlach, "Molecular genetics in acute myeloid leukemia," Current Opinion in Oncology, vol. 22, no. 6, pp. 646-655, 2010.

[2] S. Bhatia and J. P. Neglia, "Epidemiology of childhood acute myelogenous leukemia," Journal of Pediatric Hematology/Onco$\log y$, vol. 17, no. 2, pp. 94-100, 1995.

[3] U. Creutzig, M. Zimmermann, D. Reinhardt, M. Dworzak, J. Stary, and T. Lehrnbecher, "Early deaths and treatment-related mortality in children undergoing therapy for acute myeloid leukemia: analysis of the multicenter clinical trials AML-BFM 93 and AML-BFM 98," Journal of Clinical Oncology, vol. 22, no. 21, pp. 4384-4393, 2004.

[4] G. J. L. Kaspers and U. Creutzig, "Pediatric acute myeloid leukemia: international progress and future directions," Leukemia, vol. 19, no. 12, pp. 2025-2029, 2005.

[5] H. Armendariz, M. A. Fernandez Barbieri, D. Freigeiro, F. Lastiri, M. S. Felice, and E. Dibar, "Treatment strategy and longterm results in pediatric patients treated in two consecutive AML-GATLA trials," Leukemia, vol. 19, no. 12, pp. 2139-2142, 2005.

[6] U. Creutzig, M. Zimmermann, J. Ritter et al., "Treatment strategies and long-term results in paediatric patients treated in four consecutive AML-BFM trials," Leukemia, vol. 19, no. 12, pp. 2030-2042, 2005.
[7] A. Dluzniewska, W. Balwierz, J. Armata et al., "Twenty years of Polish experience with three consecutive protocols for treatment of childhood acute myelogenous leukemia," Leukemia, vol. 19, no. 12, pp. 2117-2124, 2005.

[8] N. Entz-Werle, S. Suciu, J. van der Werff ten Bosch et al., "Results of 58872 and 58921 trials in acute myeloblastic leukemia and relative value of chemotherapy vs allogeneic bone marrow transplantation in first complete remission: the EORTC Children Leukemia Group report," Leukemia, vol. 19, no. 12, pp. 20722081, 2005.

[9] G. Kardos, C. M. Zwaan, G. J. L. Kaspers et al., “Treatment strategy and results in children treated on three Dutch Childhood Oncology Group acute myeloid leukemia trials," Leukemia, vol. 19, no. 12, pp. 2063-2071, 2005.

[10] S. O. Lie, J. Abrahamsson, N. Clausen et al., "Long-term results in children with AML: NOPHO-AML Study Group-report of three consecutive trials," Leukemia, vol. 19, no. 12, pp. 20902100, 2005.

[11] Y. Perel, A. Auvrignon, T. Leblane et al., "Treatment of childhood acute myeloblastic leukemia: dose intensification improves outcome and maintenance therapy is of no benefitmulticenter studies of the French LAME (Leucémie Aiguë Myéloblastique Enfant) Cooperative Group," Leukemia, vol. 19, pp. 2082-2089, 2005.

[12] A. Pession, R. Rondelli, G. Basso et al., "Treatment and longterm results in children with acute myeloid leukaemia treated according to the AIEOP AML protocols," Leukemia, vol. 19, no. 12, pp. 2043-2053, 2005.

[13] J. Quintana, P. Advis, A. Becker et al., "Acute myelogenous leukemia in Chile PINDA protocols 87 and 92 results," Leukemia, vol. 19, no. 12, pp. 2143-2146, 2005.

[14] Y. Ravindranath, M. Chang, C. P. Steuber et al., "Pediatric Oncology Group (POG) studies of acute myeloid leukemia (AML): a review of four consecutive childhood AML trials conducted between 1981 and 2000," Leukemia, vol. 19, no. 12, pp. 2101-2116, 2005.

[15] R. C. Ribeiro, B. I. Razzouk, S. Pounds, N. Hijiya, C.-H. Pui, and J. E. Rubnitz, "Successive clinical trials for childhood acute myeloid leukemia at St. Jude Children's Research Hospital, from 1980 to 2000," Leukemia, vol. 19, no. 12, pp. 2125-2129, 2005.

[16] F. O. Smith, T. A. Alonzo, R. B. Gerbing, W. G. Woods, and R. J. Arceci, "Long-term results of children with acute myeloid leukemia: a report of three consecutive phase III trials by the Children's Cancer Group: CCG 251, CCG 213 and CCG 2891," Leukemia, vol. 19, no. 12, pp. 2054-2062, 2005.

[17] S. Gallegos-Castorena, A. Medina-Sanson, O. Gonzalez-Ramella, F. Sánchez-Zubieta, and A. Martínez-Avalos, "Improved treatment results in Mexican children with acute myeloid leukemia using a medical research council (MRC)-acute myeloid leukemia 10 modified protocol," Leukemia and Lymphoma, vol. 50, no. 7, pp. 1132-1137, 2009.

[18] W. G. Woods, S. Neudorf, S. Gold et al., "A comparison of allogeneic bone marrow transplantation, autologous bone marrow transplantation, and aggressive chemotherapy in children with acute myeloid leukemia in remission: a report from the Children's Cancer Group," Blood, vol. 97, no. 1, pp. 56-62, 2001.

[19] B. E. S. Gibson, K. Wheatley, I. M. Hann et al., "Treatment strategy and long-term results in paediatric patients treated in consecutive UK AML trials," Leukemia, vol. 19, no. 12, pp. 2130 2138, 2005.

[20] N. S. Majhail, R. Bajorunaite, H. M. Lazarus et al., "High probability of long-term survival in 2-year survivors of autologous 
hematopoietic cell transplantation for AML in first or second CR," Bone Marrow Transplantation, vol. 46, no. 3, pp. 385-392, 2011.

[21] J. T. Horan, T. A. Alonzo, G. H. Lyman et al., "Impact of disease risk on efficacy of matched related bone marrow transplantation for pediatric acute myeloid leukemia: the Children's Oncology Group," Journal of Clinical Oncology, vol. 26, no. 35, pp. 57975801, 2008.

[22] D. Niewerth, U. Creutzig, M. B. Bierings, and G. J. L. Kaspers, "A review on allogeneic stem cell transplantation for newly diagnosed pediatric acute myeloid leukemia," Blood, vol. 116, no. 13, pp. 2205-2214, 2010.

[23] C. J. Harrison, R. K. Hills, A. V. Moorman et al., "Cytogenetics of childhood acute myeloid leukemia: United Kingdom Medical Research Council Treatment Trials AML 10 and 12," Journal of Clinical Oncology, vol. 28, no. 16, pp. 2674-2681, 2010.

[24] C. Von Neuhoff, D. Reinhardt, A. Sander et al., "Prognostic impact of specific chromosomal aberrations in a large group of pediatric patients with acute myeloid leukemia treated uniformly according to trial AML-BFM 98," Journal of Clinical Oncology, vol. 28, no. 16, pp. 2682-2689, 2010.

[25] J. J. Ortega, C. Díaz de Heredia, T. Olivé et al., "Allogeneic and autologous bone marrow transplantation after consolidation therapy in high-risk acute myeloid leukemia in children. Towards a risk-oriented therapy," Haematologica, vol. 88, no. 3 , pp. 290-299, 2003.

[26] M. Berger, I. Ferrero, E. Vassallo et al., "Stem cell transplantation as consolidation therapy for children in first-remission AML: a single-center report," Pediatric Hematology-Oncology, vol. 22, no. 7, pp. 597-608, 2005.

[27] E. Jourdan, F. Rigal-Huguet, G. Marit et al., "One versus two high-dose cytarabine-based consolidation before autologous stem cell transplantation for young acute myeloblastic leukaemia patients in first complete remission," British Journal of Haematology, vol. 129, no. 3, pp. 403-410, 2005.

[28] S. Anak, E. T. Saribeyoglu, H. Bilgen et al., "Allogeneic versus autologous versus peripheral stem cell transplantation in CR1 pediatric AML patients: a single center experience," Pediatric Blood and Cancer, vol. 44, no. 7, pp. 654-659, 2005.

[29] C. Martins, J. F. Lacerda, F. Lourenço, J. A. Carmo, and J. M. F. Lacerda, "Autologous stem cell transplantation in acute myeloid leukemia: factors influencing outcome. A 13 year single institution experience," Acta Medica Portuguesa, vol. 18, no. 5, pp. 329-338, 2005.

[30] S. Neudorf, J. Sanders, N. Kobrinsky et al., "Autologous bone marrow transplantation for children with AML in first remission," Bone Marrow Transplantation, vol. 40, no. 4, pp. 313-318, 2007.

[31] A. M. Yeager, H. Kaizer, G. W. Santos et al., "Autologous bone marrow transplantation in patients with acute nonlymphocytic leukemia, using ex vivo marrow treatment with 4-hydroperoxycyclophosphamide," The New England Journal of Medicine, vol. 315, no. 3, pp. 141-147, 1986.

[32] K. J. Selvaggi, J. W. Wilson, L. E. Mills et al., "Improved outcome for high-risk acute myeloid leukemia patients using autologous bone marrow transplantation and monoclonal antibodypurged bone marrow," Blood, vol. 83, no. 6, pp. 1698-1705, 1994.

[33] B. D. Smith, R. J. Jones, S. M. Lee et al., "Autologous bone marrow transplantation with 4-hydroperoxycyclophosphamide purging for acute myeloid leukaemia beyond first remission: a 10-year experience," British Journal of Haematology, vol. 117, no. 4, pp. 907-913, 2002.
[34] A. S. Stein, M. R. O’Donnell, A. Chai et al., "In vivo purging with high-dose cytarabine followed by high-dose chemotherapy and reinfusion of unpurged bone marrow for adult acute myelogenous leukemia in first complete remission," Journal of Clinical Oncology, vol. 14, no. 8, pp. 2206-2216, 1996.

[35] L. B. To and C. A. Juttner, "Peripheral blood stem cell autografting: a new therapeutic option for AML?" British Journal of Haematology, vol. 66, no. 3, pp. 285-288, 1987.

[36] C. Martín, A. Torres, A. León et al., "Autologous peripheral blood stem cell transplantation (PBSCT) mobilized with GCSF in AML in first complete remission. Role of intensification therapy in outcome," Bone Marrow Transplantation, vol. 21, no. 4, pp. 375-382, 1998.

[37] M. S. Tallman, W. S. Pérez, H. M. Lazarus et al., "Pretransplantation consolidation chemotherapy decreases leukemia relapse after autologous blood and bone marrow transplants for acute myelogenous leukemia in first remission," Biology of Blood and Marrow Transplantation, vol. 12, no. 2, pp. 204-216, 2006.

[38] J. Ritter, U. Creutzig, and G. Schellong, "Treatment results of three consecutive German Childhood AML trials: BFM-78, -83, and -87. AML-BFM-Group," Leukemia, vol. 6, pp. 59-62, 1992.

[39] U. Creutzig, J. Ritter, M. Zimmermann et al., "Improved treatment results in high-risk pediatric acute myeloid leukemia patients after intensification with high-dose cytarabine and mitoxantrone: results of study acute myeloid Leukemia-BerlinFrankfurt-Münster 93," Journal of Clinical Oncology, vol. 19, no. 10, pp. 2705-2713, 2001.

[40] U. Creutzig, M. Zimmerman, J. Ritter et al., "Definiont of estándar risk grop in children with AML," British Journal of Haematology, vol. 104, pp. 630-609, 1999.

[41] B. D. Cheson, J. M. Bennett, K. J. Kopecky et al., "Revised Recommendations of the International Working Group for diagnosis, standardization of response criteria, treatment outcomes, and reporting standards for therapeutic trials in acute myeloid leukemia," Journal of Clinical Oncology, vol. 21, no. 24, pp. 4642-4649, 2003.

[42] NCI Common Terminology Criteria for Adverse Events v3.0 (CTCAE), August 2006.

[43] F. Locatelli, M. Labopin, J. Ortega et al., "Factors influencing outcome and incidence of long-term complications in children who underwent autologous stem cell transplantation for acute myeloid leukemia in first complete remission," Blood, vol. 101, no. 4, pp. 1611-1619, 2003.

[44] R. J. Meyer, R. B. Davis, C. H. A. Schiffer et al., "Intensive postremission chemotherapy in adults with acute myeloid leukemia. Cancer and Leukemia Group B," The New England Journal of Medicine, vol. 331, no. 14, pp. 896-903, 1994.

[45] Z. Arlin, D. C. Case Jr., J. Moore et al., "Randomized multicenter trial of cytosine arabinoside with mitoxantrone or daunorubicin in previously untreated adult patients with acute nonlymphocytic leukemia (ANLL)," Leukemia, vol. 4, no. 3, pp. 177-183, 1990.

[46] T. Büchner, W. Hiddemann, B. Wörmann et al., "Double induction strategy for acute myeloid leukemia: the effect of highdose cytarabine with mitoxantrone instead of standard-dose cytarabine with daunorubicin and 6-thioguanine: a randomized trial by the German AML Cooperative Group," Blood, vol. 93, no. 12, pp. 4116-4124, 1999.

[47] Y. Ravindranath, A. M. Yeager, M. N. Chang et al., "Autologous bone marrow transplantation versus intensive consolidation chemotherapy for acute myeloid leukemia in childhood," The 
New England Journal of Medicine, vol. 334, no. 22, pp. 1428-1434, 1996.

[48] G. J. Ruiz-Argüelles, A. Ruiz-Argüelles, B. Pérez-Romano et al., "Non-cryopreserved peripheral blood stem cells autotransplants for hematological malignancies can be performed entirely on an outpatients basis," The American Journal of Hematology, vol. 58, pp. 161-164, 1998.

[49] D. Gómez-Almaguer, "The simplification of the SCT procedures in developing countries has resulted in cost-lowering and availability to more patients," International Journal of Hematology, vol. 76, no. 1, pp. 380-382, 2002.

[50] B. J. Lange, F. O. Smith, J. Feusner et al., "Outcomes in CCG2961, a Children's Oncology Group Phase 3 Trial for untreated pediatric acute myeloid leukemia: a report from the Children's Oncology Group," Blood, vol. 111, no. 3, pp. 1044-1053, 2008. 


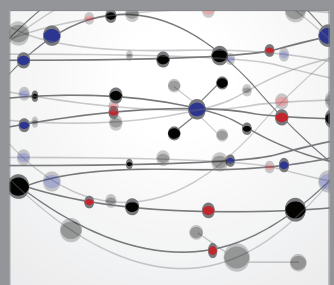

The Scientific World Journal
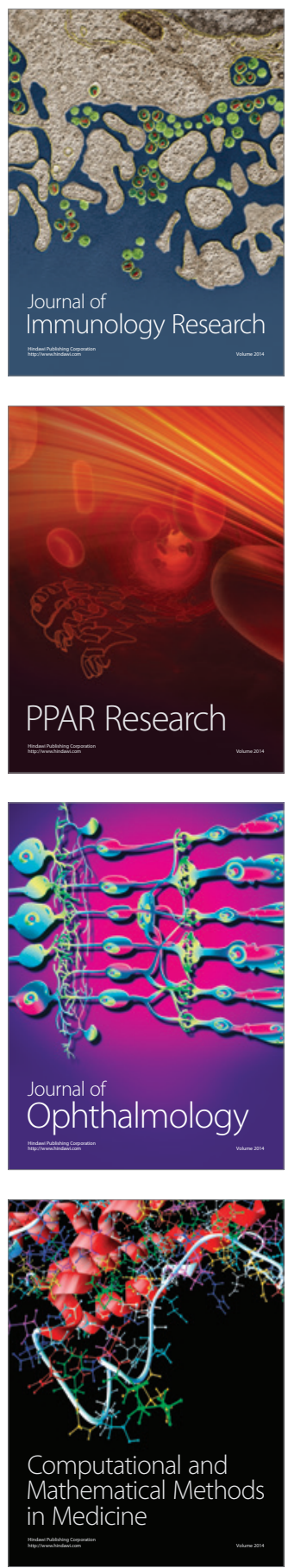

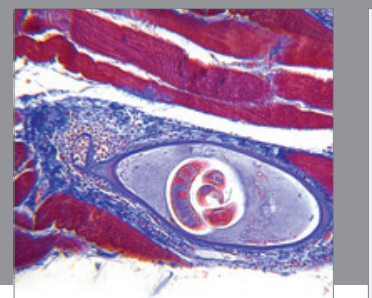

Gastroenterology

Research and Practice
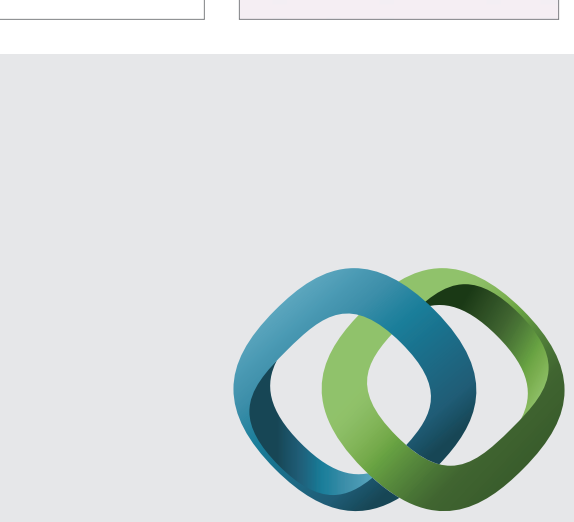

\section{Hindawi}

Submit your manuscripts at

http://www.hindawi.com
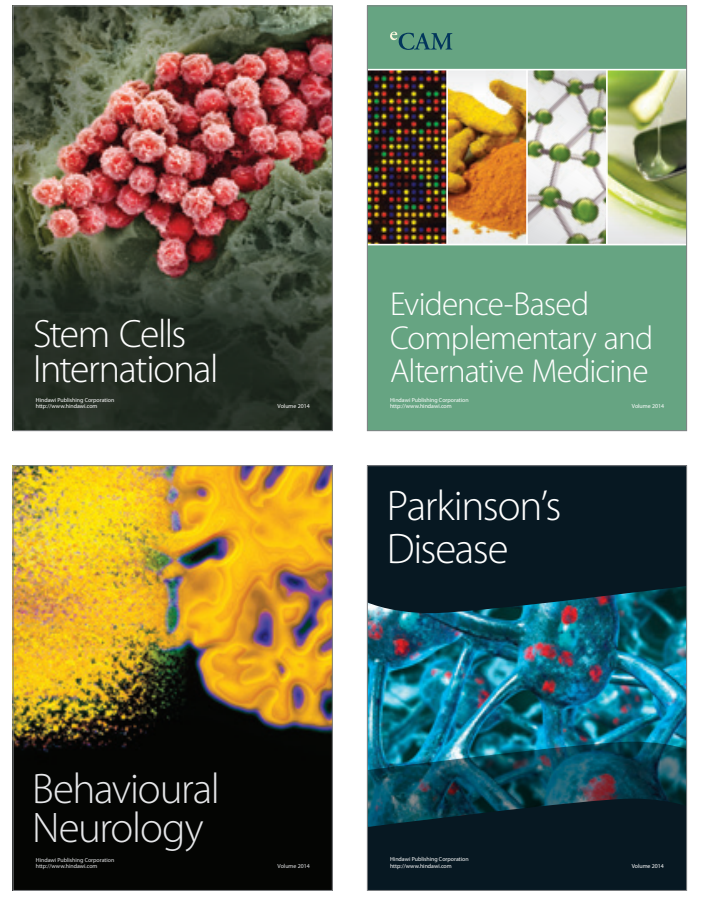
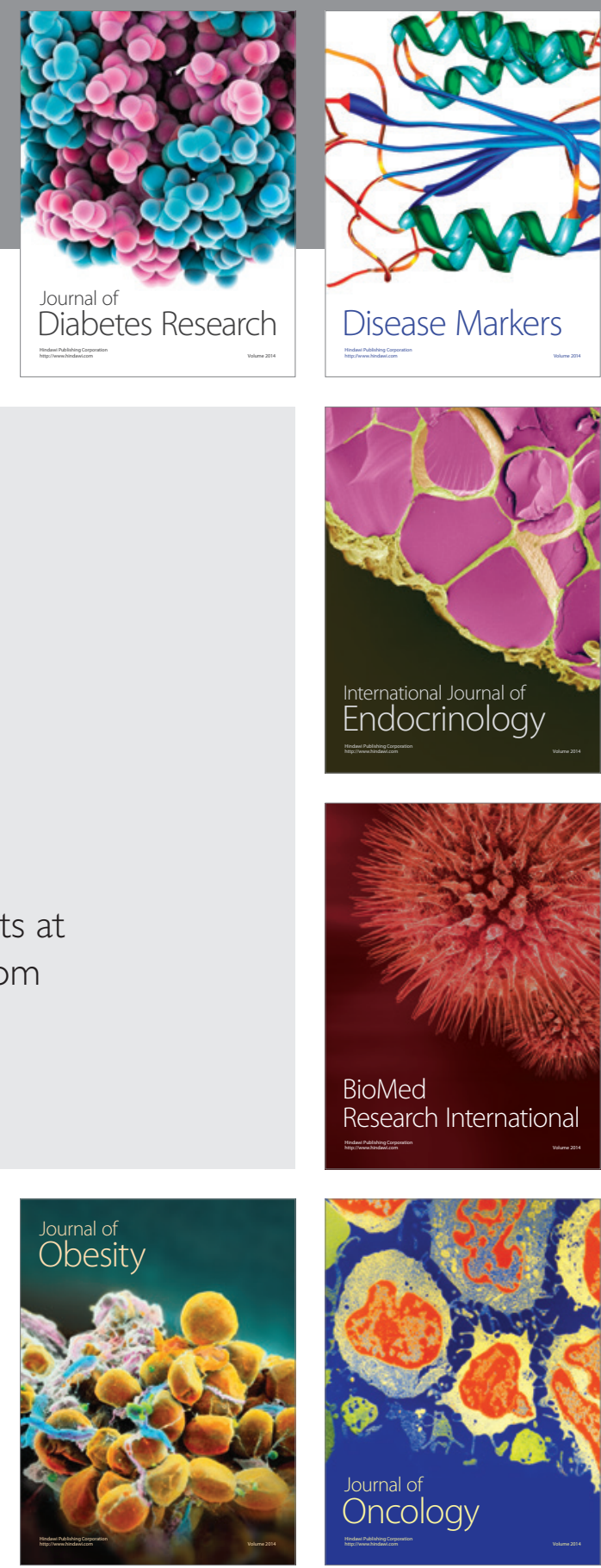

Disease Markers
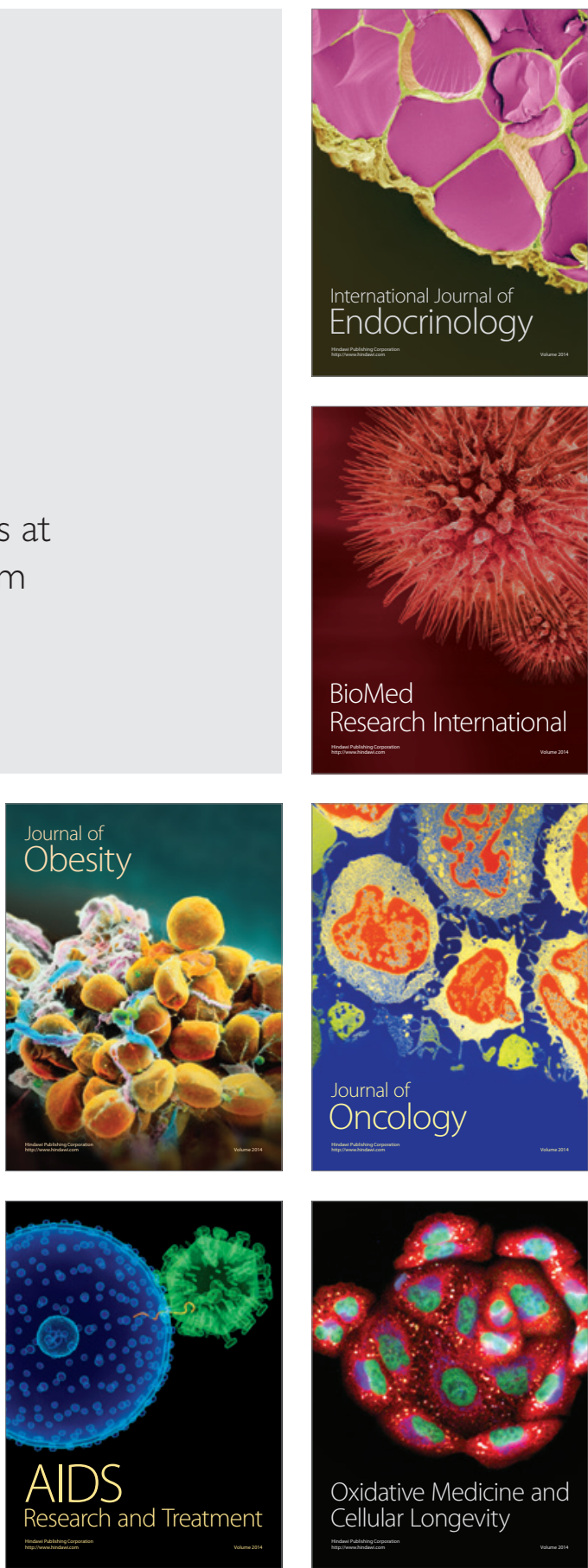